\title{
Study of Factors Associated with Acute Pharyngitis
}

\author{
Kadidiatou Doumbia-singare ${ }^{1,}$, , Fatogoma Issa Kone ${ }^{1}$, Lassine Dienta ${ }^{2}$, Samba Karim Timbo ${ }^{1}$, \\ Naouma Cisse $^{1}$, Djibril Samake ${ }^{3}$, Boubacary Guindo ${ }^{1}$, Lamine Traore ${ }^{1}$, Siaka Soumaoro ${ }^{1}$, \\ N'Faly Konate $^{1}$, Kassim Diarra ${ }^{1}$, Mohamed Amadou Keita ${ }^{1}$, Alhousseini A. G. Mohamed ${ }^{1}$ \\ ${ }^{1}$ Department of Surgery, University of Gabriel Toure, Bamako, Mali \\ ${ }^{2}$ Regional hospital of Mopti, Bamako, Mali \\ ${ }^{3}$ Reference Health Center V, Bamako, Mali
}

\section{Email address:}

kadidia22000@yahoo.fr (K. Doumbia-singare)

* Corresponding author

\section{To cite this article:}

Kadidiatou Doumbia-singare, Fatogoma Issa Kone, Lassine Dienta, Samba Karim Timbo, Naouma Cisse, Djibril Samake, Boubacary Guindo, Lamine Traore, Siaka Soumaoro, N'Faly Konate, Kassim Diarra, Mohamed Amadou Keita, Alhousseini A. G. Mohamed. Study of Factors Associated with Acute Pharyngitis. International Journal of Otorhinolaryngology. Vol. 6, No. 1, 2020, pp. 6-9. doi: $10.11648 /$ j.ijo.20200601.12

Received: January 6, 2020; Accepted: January 20, 2020; Published: February 1, 2020

\begin{abstract}
Introduction: acute pharyngitis is found in children as well as in adults. The peak incidence is between 5 and 15 years. The responsible germs are of viral or bacterial origin; the group A hemolytic beta streptococcus haunts this condition. Objective: Study the factors associated with acute pharyngitis in the ENT department of the CHU Gabriel TOURE in Bamako. Methods: A descriptive and analytical prospective study was conducted from August 30, 2015 to August 30, 2016. The study population consisted of patients admitted to the ENT department of the CHU Gabriel Touré in Bamako for acute pharyngitis. Data was collected using a questionnaire during the interview and physical examination. They were entered using Epi Data software version 3.01 and analyzed using R 3.1.2 software. Results: We collected 234 cases of pharyngitis between August 30, 2015 and August 30, 2016. The sex ratio (F/M) was 1.32. The mean age was $28.21 \pm 14.20$ years. The majority of patients presented with erythematous angina (81\%). The group A hemolytic beta streptococcus was the predominant germ (58\%). The active antibiotics on the germ were penicillin, amoxicillin, and cephalosporin. This germ was associated with erythematous angina and the risk was 3.99, CI (1.88-8.45). Complications were noted in 7 patients (3\%) upon admission, including 1 case of cervical cellulitis and 6 cases of palatine tonsil phlegmon. No deaths have been recorded. Conclusion: The aspect of the palatine tonsil does not allow to evoke a viral or bacterial etiology from where the interest to carry out a bacteriological examination in particular the culture which could orient a bacterial etiology and help the practitioner to rationalize the indication of antibiotic therapy.
\end{abstract}

Keywords: Pharyngitis, Culture, Germs, Treatment, Mali

\section{Introduction}

Acute pharyngitis also called acute angina is an inflammation of the lining of the pharynx less than 15 days old [1]. It is found in children as well as in adults [2-4]. The peak of incidence is between 5 and 15 years [5]. The germs responsible are of viral or bacterial origin $[1,4,5]$. The group A beta-hemolytic streptococcus (SGA) remains the first bacteria in question ( 25 to $40 \%$ ). Pharyngitis can progress to life-threatening complications $[6,7]$. These complications are post-streptococcal (rheumatic fever, RAA, glomerulonephritis, acute GNA), local (perithygealphlegmon, bacterial adenitis, retropharyngeal abscess) and general (sepsis). These complications are poststreptococcal (rheumatic fever, RAA, glomerulonephritis, acute GNA), local (periamydalianphlegmon, bacterial adenitis, retropharyngeal abscess) and general (sepsis).

In Mali, despite advances in antibiotic therapy, these complications are still common.

Therapeutic management requires the identification of the bacterial presence with a view to antibiotic therapy adapted to germs. This is based on performing a throat swab for direct 
examination and culture. The rapid diagnostic test (RDT) is also recommended when it is positive, this confirms the etiology at SGA [1, 8-11].

The identification of the germ is difficult in our context justifying probabilistic antibiotic therapy. This could be explained by difficulties related to sampling (insufficient equipped laboratories, financial inaccessibility to microbiological examination of patients).

The percentage of germs responsible for this disease is unknown in Mali, as are the antibiotics active on the germs.

Faced with these situations, we undertook a study on the factors associated with forms of acute pharyngitis in order to find out the bacterial ecology of acute pharyngitis which is necessary to guide ENT practitioners towards the judicious use of antibiotic therapy. This will reduce resistance to germs and complications.

\section{Patients and Methods}

This is a descriptive and analytical prospective study with the ENT and head and neck surgery department of the Gabriel Toure teaching hospital in Bamako, Mali. It was carried out over a period of 1 year from August 30, 2015 to August 30, 2016. We included in this study all the files of patients admitted for acute pharyngitis. We did not include the files of patients who received antibiotic treatment before the first consultation and of patients who did not benefit from a pharyngeal sample (these were mainly pusillanimous children).

We noted for each file:

1. The quantitative variables (age, duration of evolution) we determined the mean, the standard deviation, the extremes.

2. Qualitative variables (sex, location, symptoms of pharyngitis, history of acute pharyngitis, local and general complications, macroscopic appearance of the palatine tonsil, identified germ, antibiotics active on the germ, evolution under treatment) we determined their frequencies.

The bivariate analysis was carried out with software R. The dependent variable was the erythematous and erythematato-pultaceous aspect of acute pharyngitis. The tests used were those of CHI2 or Fisher depending on their applicability conditions. The confidence interval was $95 \%$, and the difference considered significant if $\mathrm{p}$ was less than 0.05 .

The multivariate analysis was done with software $\mathrm{R}$. The modeling of pharyngitis was done by logistic regression.

\section{Results}

We have identified 234 cases of pharyngitis in 1 year.

The mean age was $28.21 \pm 14.20$ years. The extreme ages were 2 and 75, with a median of 29 .

The majority of patients were over 30 years of age (42\%).

The series included 133 female patients (57\%) and 101 male patients $(43 \%)$ with a sex ratio $(\mathrm{F} / \mathrm{M})$ of 1.32 .

As for symptoms, dysphagia was predominant (94\%).

The mean duration of symptom progression was 5 days with extremes of 1 and 15 days.

The mean duration of symptom progression was 5 days with extremes of 1 and 15 days.

Angina was macroscopically erythematous in $81 \%$ of cases and erythematato-pultacea in $19 \%$ of cases.

Bacteriologically: Group A Streptococci have been isolated in $58 \%$ of cases. The amoxicillin-clavulanic acid combination was the most active antibiotic on the germ (61\%). The average duration of antibiotic therapy was 8, 66 days with extremes of 5 and 10 days.

The evolution was marked by complications 7 cases $(3 \%)$ including 1 case of cervical cellulitis and 6 cases of peritonsillaryphlegmon. These complications were observed upon admission of patients. There were no deaths.

In bivariate analysis, Table 1 shows the links between erythematous angina and the signs.

Table 1. Link between erythematous appearance and signs.

\begin{tabular}{|c|c|c|c|}
\hline \multirow{2}{*}{ Variables } & \multicolumn{2}{|c|}{ Erythematous angina } & \multirow{2}{*}{$P$ value } \\
\hline & Presente n (\%) & absent n (\%) & \\
\hline \multicolumn{4}{|c|}{ Pharyngeal pain } \\
\hline Yes & $178(94)$ & $41(93)$ & \multirow{2}{*}{0,67} \\
\hline No & $11(6)$ & $4(9)$ & \\
\hline \multicolumn{4}{|l|}{ Fever } \\
\hline Yes & $78(42)$ & $26(57,8)$ & \multirow{2}{*}{0,06} \\
\hline No & $111(58)$ & $19(42,2)$ & \\
\hline \multicolumn{4}{|l|}{ Erache } \\
\hline Yes & $34(18)$ & $10(22,2)$ & \multirow{2}{*}{0,27} \\
\hline No & $155(82)$ & $35(77,8)$ & \\
\hline
\end{tabular}

Erythematous angina was statistically significant with fever $(p=0.06)$.

Group A streptococcus was the most frequently encountered germ in erythematous angina and the link was statistically significant $(\mathrm{p}=0.003)$.

In multivariate analysis, a complete model was constructed only with the variables having a $\mathrm{p}<0.05$.

Table 2. Results of the determinants of erythematous angina on the qualitative variables in multivariate analysis.

\begin{tabular}{llll}
\hline Variables & Crude OR (95\%CI) & Adj. OR (95\%CI) & P (Wald's test) \\
\hline FIEVER: no vs yes & $0.51(0.27,0.99)$ & $0.44(0.21,0.91)$ & 0.026 \\
COMPLICATION: no vs yes & $0.03(0,0.3)$ & $0.03(0,0.24)$ & 0.001 \\
StreptococcusA: no vs yes & $2.8(1.43,5.48)$ & $3.99(1.88,8.45)$ & $<0.001$ \\
\hline
\end{tabular}

Patients who do not have Streptococcus A are 3.99 times more likely not to develop erythematous angina.

Uncomplicated patients are 0.03 times more likely not to develop erythematous angina. Those who do not have a fever are 2.27 times less likely to not develop erythematous angina. 


\section{Discussion}

Acute angina is a frequent pathology, we received 234 cases in 1 year on the other hand Gorge $\mathrm{N}$ et al received 23130 cases in 1 year [12].

The average age of the patients was 28.21 years. The highest frequency of angina was found in patients over 30 years of age $(42 \%)$ while it was $11 \%$ in patients between the ages of 1 and 10 years. However, this difference was not statistically significant $(\mathrm{p}=0.52)$.

On the other hand, other studies have reported that the peak of angina was at the age group 5 and 15 years and these authors did not find an association between age and angina $(\mathrm{p}$ $=0.06)[4.5]$.

The usual clinical signs of angina are fever, odynophagia, dysphagia, cough, lymphadenopathy, redness of the pharynx sometimes associated with white spots. The dominant symptom was odynophagia (94\%). Although common, it was not significantly associated with erythematous angina $(\mathrm{p}=$ $0.6)$ and erythematato-pultacea $(\mathrm{p}=1)$. This symptom is classic regardless of the type of angina $[1,2]$.

As for fever, it was associated with erythematous angina $(\mathrm{OR}=0.44 ; \mathrm{CI}=0.21,0.91)$ and erythematato-pultacea $(\mathrm{OR}$ $=2.27 ; \mathrm{CI}=1.12,4.58)$. We share the same observation with literature.

An examination of the oropharynx makes the clinical diagnosis of angina. It makes it possible to distinguish on the appearance of the oropharynx from erythematous or erythematato-pultaceous, pseudo-membranous, ulcerative and ulcerative-necrotic, finally vesicular angina $[1,2,7]$. Erythematous angina was predominant $(81 \%)$ followed by erythemaro-pultacea angina (16\%) as reported in the literature $(1,3)$. These two aspects do not prejudge the bacterial or viral etiology $[1,3,10,11]$.

Among the germs found in the present study, group A hemolytic beta streptococcus (SGA) was the most frequent $(58 \%)$. This rate was lower than that reported by Bouskraoui $\mathrm{M}$ et al who isolated 65 group A hemolytic beta streptococci in 697 samples, ie $9.1 \%$ [3].

We did not note a significant difference between the frequency of these two aspects and age $(p=0.33)$ while for other authors the data differ $(25-40 \%$ for children against 10 $25 \%$ for adults) $[4,12]$.

These two aspects (erythematosus and erythematatopultaceae) do not prejudge the bacterial or viral etiology. Strep throat can be erythematous or erythematato-pultacea $[1$, $3,13]$.

Group A hemolytic beta streptococcus was associated with erythematous angina $(\mathrm{OR}=3.99 ; \mathrm{CI}=1.88,8.45)$. On the other hand, it was not associated with erythematato-pultacea angina $(\mathrm{p}=0.29)$.

The identification of the germ is based on the culture of the pharyngeal sample and the practice of the rapid diagnostic test (RDT). Culture is only indicated if the RDT is negative and there are risk factors for rheumatic fever (RAA) $[1,3,13]$. The unavailability of the TDR led us to culture the samples with a waiting time of 72 hours. This time is longer than that recommended by other authors $24-48$ hours $[1,3,4$, 13]. The culture has a sensitivity and specificity of $90-95 \%$ $(3,4.5)$. It allowed germ isolation in $76 \%$ and Group A Streptococcus represented 58\%. On the other hand, for Benouda et al out of 697 pharyngeal samples, the culture only isolated Group A Streptococcus in 65 cases, ie 9.3\% [4]. For Regoli $\mathrm{M}$ et al, the TDR was $98 \%$ specific and the culture was $97 \%$, the difference between the two tests was not statistically significant [2].

Angina may progress to loco-regional suppurative complications (peri-tonsillaryphlegmon, retropharyngeal abscess, cervical adenitis, cervical cellulitis) and poststerptococcal syndromes (acute glomerulonephritis, acute rheumatic fever, chorea Sydenham) [1, 3, 4, 14]. We noted complications with peri-tonsillaryphlegmon type in 7 patients upon admission. These complications can occur even after well-administered antibiotic treatment for angina. The preventive treatment of antibiotics on the occurrence of these complications is not well established [3, 5, 6, 13]. Among these 7 cases, the SGA was isolated in 5 patients. These complications were attributed to the SGA. This result is in contradiction with that of George $\mathrm{N}$ et al who had noted 13 cases of peri-tonsillaryphlegmon which were not related to SGA in 953 patients with acute pharyngitis [12].

Antibiotic treatment of angina is not systematic, due to the prevalence of viral etiology. The most frequently used antibiotics are: penicillin, aminopenicillins, betalactamase inhibitors, cephalosporins, macrolides $[5,6,12]$. Several authors agree to suggest penicillin as the antibiotic of choice $[2-4,13]$. In the present study $86 \%$ of the patients received an antibiotic before the bacteriological result and the combination amoxicillin - clavulanic acid was the most used antibiotic $61 \%$ and the duration of the treatment was $8-10$ days.

The number 3 antibiotic family was the most active $67 \%$ on the germs involved in erythematous angina and erythematato-pultacea. It included penicillin, the aminopenicillin and beta-lactamase inhibitor, the Macrolides, was the most active $67 \%$ on the germs involved in erythematous and erythematato-pultacea. Nazgoul A et al in their series of 200 cases of GBS in children reported that this germ was sensitive to amoxicillin $36.2 \%$, to cephalosporins $38.7 \%$ and to macrolides $26.2 \%$ [15].

The outcome was favorable in all patients. We did not notice a recurrence.

\section{Limits}

Information reported by parents about symptoms is often insufficient when it comes to children who cannot express themselves properly.

The interpretations of our results must take into account above all the quality of the sample which is not always easy in children. The conditions of transport of the samples and the storage of the swabs in the cold can also influence the results. 


\section{Conclusion}

Acute pharyngitis is a common condition and occurs in both children and adults. The aspect of the amygdala does not allow to evoke a viral or bacterial etiology from where the interest to carry out a bacteriological examination in particular the culture which could orient a bacterial etiology and help the practitioner to rationalize the indication of the antibiotic therapy.

\section{References}

[1] Coloigner V. Les angines. EMC (Traité de Médecine). 2010; 6-0400. $7 \mathrm{p}$.

[2] Regoli M, Chiappini E, Bonsignori F, Galli L, Martino M. Update on the management of acute pharyngitis in children. Italian Journal of Pediatrics 2011, Vol 37 pp. 10.

[3] Bouskraoui M, Abid A. Anginesaigues. Rev Mar Mal Enf. 2013, Vol 31, pp. 5-15.

[4] Benouda A, Sibile S, Ziane Y, Elouennass M, Dahani K, Hassani A. Place de Streptococcus pyogenes dans les angines au Maroc et état actuel de la sensibilité aux antibiotiques. Pathologie Biologie. 2009, Vol 57, pp. 76-80.

[5] François M. Le traitement des angines. Ann Otolaryngol Chir cervicofac, 2005, Vol 122, pp. 59-62.

[6] Everette MT. Antibiotics in the treatment of tonsillitis. Journal of royal college of general practitioners, 1975, Vol. 25, pp. 317-325.

[7] Barbosa Junior AR, Oliveira CD, FernandesFontes MJ, FacuryLasmar LM, Moreira Charmgos PA. Diagnostic of streptococcal pharyngotonsillitis in children and adolescents: clinical picture limitations. Rev Paul Pediatr., 2014, Vol 32, pp. 285-291.

[8] Jensen A, Fagö-Olsen H, Sorensen CH, Kilian M. Molecular mapping to species level of the tonsillar Crypt microbiota associated with heath and recurrent tonsillitis.

[9] Plos ONE, 2013, Vol 8, pp. 14.

[10] Barry B, Kania R, Richini C. Les infections pharyngées. Les monographies amplifon. Paris, 2014, P. 82.

[11] Nakoul G, Hickner J. Management of adults with acute Streptococcal pharyngitis: Minima value for Backup strep testing and overuse of antibiotics. J gen Intern Med, 2012, Vol 28, pp. 830-4.

[12] Stelter K. Tonsillitis and sore throat in children. Otorhinolaryngol Head Neck Surg. 2014, Vo 13, pp. 7.

[13] Georges N, Hickner J. Management of adults With acute streptococcal pharyngitis: Minimal value for backup strep testing for overuse of antibiotics. JGIM, 2012, Vol. 13, pp. 830-834.

[14] Andrew M, Nizet V, Mandel D. Improved diagnostic accuracy of group A streptococcal pharyngitis using real- time biosurveillance. Ann Intern Med, 2011, Vol. 6, pp 2-14.

[15] Lin YY, Lee JC. Bilateral peritonsillarabscesses complicating acute tonsillitis. CMAJ. 2011, Vol. 183, pp. 12-77.

[16] Nazgoul A, Yamano Y, Saatova G, Alybeava M, Nishioka K, Nakajima T. Prevalence of group A b-haemolytic streptococcus among children with tonsillopharyngitis in Kyrgyzstan: the difficulty of diagnostic and therapy. The Open Rheumatology Journal, 2010, Vol. 4, pp. 39-46. 